\title{
Intercalative Interaction of Asymmetric Copper(II) Complex with DNA: Experimental, Molecular Docking, Molecular Dynamics and TDDFT Studies
}

\author{
Wei Hu, ${ }^{\dagger}$ Suwen Deng, ${ }^{\dagger}$ Jianyin Huang, ${ }^{\dagger}$ Yanmei Lu, ${ }^{\dagger}$ Xueyi Le, ${ }^{*}$ \& Wenxu Zheng ${ }^{*}{ }^{\dagger}$ \\ ${ }^{\dagger}$ Department of Applied Chemistry, South China Agricultural University, Guangzhou \\ 510642, China
}

${ }^{\ddagger}$ Environmental Future Center, Griffith University, Gold Coast campus, Queensland 4215, Australia

${ }^{\S}$ Institute of Biomaterial, South China Agricultural University, Guangzhou 510642, China

*Corresponding authors:

wzheng@scau.edu.cn (Wenxu Zheng); lexy@scau.edu.cn (Xueyi Le) 


\section{ABSTRACT}

A comprehensive research protocol including experiments and calculations was employed to investigate the intercalative interaction between metallointercalator copper(II) complex and DNA. The intercalative binding mode has been validated by UV spectra, fluorescence spectra, CD spectra and viscosity measurements. The classic molecular dynamics simulation was first carried out to investigate the intercalative interaction between asymmetric copper(II) complex and DNA. A new analytical method was proposed to simulate the dynamically changing absorption spectra of complex/DNA intercalation system. According to the established model, the changing process of the electronic absorption spectra for complex/DNA intercalation system can be predicted accurately. A rational explanation for change law of absorption spectra has been proposed. Moreover, the analyses of the frontier orbital reveal that the red shift of the absorption spectra is due to the increase of $\pi$ orbital energy caused by the coupling of the $\pi$ orbital of the intercalated ligand with the $\pi$ orbital of DNA. This cause of red shift of spectra is completely different from the previous inference. All these insights are of crucial importance for correctly analyzing the absorption spectra of intercalative interaction, as well as for explaining the macroscopic phenomena observed in experiments at the molecular level.

\section{KEYWORDS}

metallointercalators, intercalation, molecular dynamics, TDDFT, absorption spectra 


\section{INTRODUCTION}

Over the past decade, the interactions of transition metal complexes with DNA have received great attention and become one of the hot topics owing to their potential applications such as DNA-structure probes $^{1}$, DNA-dependent charge transport probes $^{2}$, DNA-molecular "light switches"3, DNA-photocleavage reagents", and anti-cancer drugs ${ }^{5}$. Although there are a lot of complexes that can be used for these applications, metallointercalators, transition metal complexes which bind DNA primarily by intercalation, are considered the most effective class of molecules ${ }^{2.6}$. Intercalators containing an extended aromatic planar ligand intercalate into DNA base pairs with $\pi$-electron system interactions, and the intercalative interaction can stabilize, lengthen, stiffen, and unwind the DNA double helix ${ }^{7}$. These structural changes can influence biological activity of nucleic acid, which often causes the inhibition of transcription and replication, and DNA repair processes. However, it is difficult to essentially understand the information mentioned above, unless we can obtain more details of drug-nucleic acid interactions at the molecular level ${ }^{8}$.

Although a wealth of metallointercalators have been fabricated and their interactions with DNA have been extensively studied by UV-vis absorption spectra, emission spectra, viscosity measurements, circular dichroism spectra and gel electrophoresis, etc ${ }^{6.9}$, it is still difficult to elucidate the structural details of complex-DNA adducts from the X-ray and NMR studies. In this situation, the theoretical approach is a useful method to get the detailed information that is hardly to 
obtain from the experimental investigations. To the best of our knowledge, only a few theoretical calculations have been performed to predict the binding mode between metallointercalators and nucleic acid at molecular docking ${ }^{10}$, molecular mechanics $(\mathrm{MM})^{11}$, quantum mechanics/molecular mechanics $(\mathrm{QM} / \mathrm{MM})^{8 b .12}$, density functional theory $(\mathrm{DFT})^{13}$ level. However, it is well known that the quantum chemical calculations for the complex-DNA interactions are too expensive since these systems are usually too large for general computer capabilities, and it can normally only process the system with a complex and two base-pair fragments ${ }^{13}$. Molecular dynamics (MD) calculations provide powerful tools for understanding the structural and dynamic characterization of biological macromolecules involving nuclear acid ${ }^{14}$, which could further guide us in solving various biological problems, such as DNA-binding/cleavage mechanisms ${ }^{15}$. However, the accuracy of MD simulation results for the metal complexes basically relies on the force field parameters of complexes ${ }^{15-16}$. Recently, we found that MD method was used to study the structural predictions for the interaction of transition metal complexes with DNA through groove binding ${ }^{15.16 \mathrm{~b} . \mathrm{c}}$. Moreover, there were few MD calculations for the binding between metallointercalators (Pt(II) and $\mathrm{Ru}(\mathrm{II})$ complexes) and nucleic acid. ${ }^{17}$ This motivated us to explore the intercalative interaction between asymmetric $\mathrm{Cu}$ (II) complex and DNA by MD simulation. In addition, based on the simulated geometry of metallointercalator-DNA adduct, the previous researches concentrated on the analysis of spectral property using time-dependent DFT (TDDFT) calculations ${ }^{10.12 .18}$. The existing theoretical analytical method for the absorption spectrum of 
complex/DNA intercalation is to directly compare the calculated spectrum of adduct with the experimental spectrum of complex/DNA interaction. ${ }^{10.12 .18}$ This method can be successfully applied to the analysis of the main experimental spectral features of metallointercalator-DNA adduct. However, as we know, with the gradual adding of DNA into complex solution, more and more complex molecules can insert into DNA. This dynamic process could be reflected by a gradual hypochromism along with red shift of absorption band of the complex. Until now, there are no related theoretical reports on the dynamic changing process of UV spectrum. Moreover, in experiments, equal quantity of CT-DNA was added to both the complex solution and the reference solution to eliminate the absorbance of DNA itself while measuring the absorption spectra. Unfortunately, this factor was not considered in all related theoretical researches. In addition, in some researches, an interesting spectral phenomenon has been observed ${ }^{19}$ : initially, the red shift increases slowly with the addition of DNA, but when the $[\mathrm{DNA}] /[$ complex] ratio reaches a certain level, the increase of red shift begin to accelerate. The exact cause of this irregular change is still unclear. Based on above reasons, we present here a new analytical method to explore these issues by simulating the dynamic absorption spectra for complex/DNA intercalation.

In the present work, MD simulation was carried out to investigate the intercalation between DNA and an asymmetric metallointercalator $[\mathrm{Cu}(\mathrm{HPB})(L-\mathrm{Ala})]^{+}(\mathrm{HPB}=2(2$-pyridyl $)$-benzimidazole, and $L$-Ala $=L$-alaninate $) .{ }^{20}$ This copper complex is an important class of artificial metallonucleases that have been extensively studied by using experimental methods in our laboratory. ${ }^{9 \mathrm{~d}}$ 
Moreover, the unsymmetrical structure of this complex containing an aromatic planar ligand as an intercalative ligand and an amino acid as an ancillary ligand requires more force field parameters for the MD simulations, which renders it more representative than the symmetrical complexes. Here, we examined the simulating

effect of classical AMBER force field parameters and RESP charges for $[\mathrm{Cu}(\mathrm{HPB})(L-\mathrm{Ala})]^{+}$complex based on DFT calculation. In addition, the common experimental methods for the research of interaction between DNA and complexes and several theoretical approaches were performed to validate our simulative results.

\section{EXPERIMENTAL AND COMPUTATIONAL METHODS}

\section{DNA binding experiments}

See SI1 in supporting information.

\section{Computational Methods}

Structural and Electronic characteristics for complex. $\mathrm{DFT}^{21}$ calculation was applied to optimize the structure of $[\mathrm{Cu}(\mathrm{HPB})(L-\mathrm{Ala})]^{+}$complex. Becke's three-parameter nonlocal exchange functional along with the Lee-Yang-Parr nonlocal correlation functional (B3LYP $)^{22}$ was employed. The standard valence double- $\xi$ basis set augmented with d-type polarization functions and s- and p-type diffuse functions, $6-31+\mathrm{G}^{* 23}$, was used. Harmonic frequency calculation at the same level was performed to confirm that the optimized structure was stable. All the DFT calculations were carried out with suite of programs GAUSSIAN03 ${ }^{24}$. 
Docking conformation. To estimate the initial structure of the metallointercalator-DNA binding system, the optimized structure of complex was docked with DNA containing a iodinated 8-mer oligonucleotides d(5'-G-dIU-TGCAAC-3') ${ }^{25}$ (PDB code 454D) using the Autodock4.2 Program ${ }^{26}$. The water molecules and the ligand were removed from the 454D, and Gasteiger charges were added to the complex by Autodock Tools (ADT) before performing docking calculations. The binding site was centered on the DNA molecule and a grid box was created with $60 \times 60 \times 60$ points. The rigid docking protocol and 50 runs of the Lamarckian genetic algorithm for searching ligand conformations were performed. In addition, other parameters were used for the default settings.

Parameterization for MD simulations. A modification of the AMBER FF99SB force field and the generalized $\mathrm{GAFF}^{27}$ force field were applied for the DNA and complex, respectively. For the complex, the restrained electrostatic potential (RESP) ${ }^{28}$ charge approach was used to derive atomic charges since RESP charge is one of the most widely used and well-behaved charges for MD simulations. First, the electrostatic potential representing atomic charges for the investigated complex based on the optimized geometries were calculated at B3LYP/6-31+G* level using the Merz-Kollman scheme ${ }^{29}$. Then the RESP charges were derived using Antechamber. For MD simulations, the classic copper parameters $\mathrm{r}_{\mathrm{vdw}}=0.96 \AA$ and $\varepsilon_{\mathrm{well}}=0.01$ $\mathrm{kcal} / \mathrm{mol}$ were appointed ${ }^{30}$, and missing parameters of complex were built using the parmcal tool of the AMBER package on the basis of the structure determined by DFT calculation (selected force field parameters were listed in SI2). 
Simulated system. In order to make our simulated system more representative, the iodinated dIU base of DNA in the docking result was manually altered into native thymine $^{25}$, so the final DNA fragment for MD simulations was the 8 -mer duplex d(5'-GTTGCAAC-3'). The simulated complex-DNA adduct contained a $\mathrm{d}\left(5^{\prime}-\mathrm{GTTGCAAC}-3^{\prime}\right)$ duplex and the $[\mathrm{Cu}(\mathrm{HPB})(L-\mathrm{Ala})]^{+}$complex intercalated into the GC step of DNA. Moreover, MD simulations for free complex without DNA and free DNA duplex without complex were respectively performed in order to check the accuracy of parameterization and make a comparative study. For each of the simulated systems, the TIP3P water model box extended $12 \AA$ in all directions was added and the total charge was neutralized by adding appropriate $\mathrm{Na}^{+}$or $\mathrm{Cl}^{-}$ions at physiological concentration in the box.

MD simulations. Periodic boundary conditions (PBC) were applied and Particle Mesh Ewald (PME) method ${ }^{31}$ was used to calculate the electrostatic interactions. The values of nonbonded cutoff were set to $10 \AA$ for the real part of the electrostatic interactions and for the van der Waals interactions. Bonds involving hydrogen were constrained and a time step of $1 \mathrm{fs}$ was used. Before the MD run, the energy of these systems was minimized to remove conflicting contacts. First, water molecules and counterions were relaxed through 10000 minimization cycles (2000 steepest descent plus 8000 conjugate gradients) while the solute was constrained using a harmonic potential with a force constant of $100 \mathrm{kcal} \mathrm{mol}^{-1} \AA^{-2}$. Then, the whole system was relaxed for 2000 conjugate gradients cycles with no restraints. The systems were then heated gradually from 0 to $300 \mathrm{~K}$ in 100 ps of NVT MD with a force constant of 50 kcal $\mathrm{mol}^{-1} \AA^{-2}$ on the solute. Subsequently, restraints were then released for $100 \mathrm{ps}$ of simulation at $300 \mathrm{~K}$. Then, $200 \mathrm{ps}$ of NPT MD were carried out at normal pressure (1 atm.). Finally, for each of systems, $10 \mathrm{~ns}$ simulations were carried out for data 
collection with coordinates saved every 1 ps during the entire process. All minimizations and MD simulations were performed by using the PMEMD module of AMBER 12 program package ${ }^{32}$. The Root Mean Square Deviations (RMSD), which were used to assess the relative motions and the stability of the whole system, were calculated using the ptraj module of AMBER. Structural parameters of DNA (rise, twist) were calculated with X3DNA program ${ }^{33}$.

The calculation of absorption spectra. The geometries for the absorption spectrum calculations were obtained from the corresponding MD simulation results at $10 \mathrm{~ns}$. Since the obtained DNA-complex adduct was a macromolecular system, we sheared the DNA fragment, and only the complex with two base pairs (GC/CG) around it was retained. ${ }^{10}$ Based on the sheared model, the electronic absorption spectrum in methanol solution was calculated by the time-dependent DFT (TDDFT) at the level of b3lyp/3-21g* associated with the conductor polarizable continuum model $(\mathrm{CPCM}){ }^{10}$ Moreover, to further study the insertion behaviors of the complex, the absorption spectra of free complex and free GC/CG base pairs were calculated at the same level. The GC/CG was sheared from the free DNA. On the basis of the TDDFT calculations, the spectra were afterward simulated, using GaussSum $2.2,{ }^{34}$ with the fwhm value of $6000 \mathrm{~cm}^{-1}$.

\section{RESULTS AND DISCUSSION}

DNA binding experiments. The absorption spectral traces of the complex with an increasing concentration of CT-DNA are shown in Figure 1. Considering the effect of DNA on the solution volume, the addition of CT-DNA was stopped when the $[\mathrm{DNA}] /[$ complex $]$ ratio increased to a large value of 30 . Upon incremental additions 
of CT-DNA to the complex, the $\pi \rightarrow \pi^{*}$ absorption bands of the complex exhibited a significant hypochromism of about $40 \%$ at $331 \mathrm{~nm}$ along with a minor red shift $(\Delta \lambda \approx$ $4 \mathrm{~nm}$ ). These results are agreement with the intercalation of the ligand between the stacking of bases. ${ }^{35}$ The $K_{\mathrm{b}}$ value for the complex was estimated as $2.4 \times 10^{3} \mathrm{M}^{-1}$, which reveals that the complex has relatively weak DNA binding affinity. As shown in the figure, the absorption band of the complex presents a sustainable slow red shift with the increasing $[\mathrm{DNA}] /[$ complex] concentration ratio, which indicates that the DNA/complex interaction system has not reached their equilibrium state. We therefore reason that the absorption band may continue to red shift with an increasing number of CT-DNA.

Viscosity measurements are sensitive to length changes of DNA and are regarded as the most critical test for binding mode. ${ }^{36}$ The effects of the complex and EB on the viscosities of CT-DNA are shown in Figure S1 (see SI3). EB, a well-known DNA intercalator, can strongly raise the relative viscosity by lengthening the DNA double helix through intercalation. As revealed in Figure S1, upon increasing the amounts of the complex, the relative viscosity of DNA increases similarly to the behavior of EB. This observation suggests that the principal mode of DNA binding by the complex involves base-pair intercalation, ${ }^{37}$ which is in agreement with the results obtained by electronic absorption, fluorescence spectroscopy (see SI4) and circular dichroic spectroscopy (see SI5). 
Structural and electronic characteristics. The optimized geometry of $[\mathrm{Cu}(\mathrm{HPB})(L-\mathrm{Ala})]^{+}$with the atomic labels is shown in Figure 2. The complex has a square-planar structure, in which the central $\mathrm{Cu}^{2+}$ cation coordinates with three $\mathrm{N}$ atoms and one $\mathrm{O}$ atom. Furthermore, the DFT computational results for some selected bond lengths and angles of the complex are labeled in Table 1 along with the available experimental data. The results show that the quantum-chemically optimized geometry of this complex is very similar to the original structures derived from X-ray crystallography. The calculated bond lengths, angles and dihedral angles differ from experimental ones by less than $0.07 \AA(\mathrm{Cu}-\mathrm{N} 4), 3.4^{\circ}(\mathrm{N} 1-\mathrm{Cu}-\mathrm{N} 4)$ and $0.7^{\circ}$ (O1-N3-N1-N4) respectively. Therefore, we conclude that the DFT calculations at B3LYP/6-31+G* level provide a fair description of $[\mathrm{Cu}(\mathrm{HPB})(L-\mathrm{Ala})]^{+}$complex. Furthermore, the calculated results are suitable to be used to built force filed parameters and to derive RESP charges for the $[\mathrm{Cu}(\mathrm{HPB})(L-\mathrm{Ala})]^{+}$complex.

Initial structure for MD simulation. The docking results show that the complex mainly binds to DNA with an intercalation mode. The most stable configuration with the binding energy of $-8.44 \mathrm{kcal} / \mathrm{mol}$ was chosen as the initial structure for MD simulation (see Figure S4a in SI6). Two strong hydrogen bonds between the H4b atom on $L$-Ala ancillary ligand and two $\mathrm{O}$ atoms on DNA molecule can be observed in adduct, and the two bond lengths of $\mathrm{N} 4-\mathrm{H} 4 \mathrm{~b} \cdots \mathrm{O}$ are $1.903 \AA$ and $2.657 \AA$, respectively (see Figure S4b in SI6). 
Molecular dynamics simulations. Potential energies for $[\mathrm{Cu}(\mathrm{HPB})(L-\mathrm{Ala})]^{+}, \mathrm{DNA}$ and $[\mathrm{Cu}(\mathrm{HPB})(L-\mathrm{Ala})]^{+}$-DNA adduct during $10 \mathrm{~ns}$ simulations and RMSD of all non-hydrogen atoms of these investigated systems with reference to their first structures are shown in Figure S5a-d (see SI7). Obviously, the energies for the three systems are stable during the whole simulations (see Figure S5a-c), strongly indicating that the equilibrium has been reached. The RMSDs with the mean values of $0.31 \AA$ for the complex , 1.76 for DNA and $1.54 \AA$ for adduct further indicate that each of these systems has reached an dynamical equilibrium during the whole simulations (see Figure S5d).

In order to check the accuracy of force field parameters for the DNA and complex, $10 \mathrm{~ns}$ MD simulations for free $[\mathrm{Cu}(\mathrm{HPB})(L-\mathrm{Ala})]^{+}$complex and free DNA were performed. For the free complex, the initial structure was taken from the DFT optimized structure. As shown in Table 1, the average structural parameters of MD simulations are similar to those of experimental data, and even some bond parameters are more close to the experimental data than DFT calculations. For example, the average bond length of $\mathrm{Cu}-\mathrm{N} 1$ around $1.99 \mathrm{~A}^{\circ}$ is the same as the value in the crystal structure, while the corresponding bond length in DFT optimized structure is $2.02 \mathrm{~A}^{\circ}$. Moreover, the obtained trajectories were analyzed using RMSD with reference to the experimental structure (see Figure S6a in SI8). The RMSD of non-hydrogen atoms of the complex is small (averaged RMSD $=3.42 \AA$ ). The good agreement between simulation and experimental observation for $[\mathrm{Cu}(\mathrm{HPB})(L-\mathrm{Ala})]^{+}$suggests that the MD simulation using our developed force field parameters and RESP charges can 
satisfactorily reproduce the experimental structure. On the other hand, we investigated the motion of the free DNA fragment d(5'-GTTGCAAC-3') extracted from the docking results without the complex by MD simulation. The detailed structural parameters between two consecutive base pairs in d(5'-GTTGCAAC-3') obtained from the crystal structure and MD results are listed in Table 2, and the corresponding structures for free DNA are shown in Figure 3. The MD results indicate a structural evolution characterized by a considerable narrowing of the distance between GC/GC consecutive base pairs (from $7.37 \AA$ to $3.39 \AA$ ), while the other distances have no significant changes. Moreover, the larger RMSD values for free DNA with the reference to the initial structure show that the structure of the DNA undergoes a considerable change during the MD simulations (see Figure S6b in SI8). All these results reveal that the initial structure of free DNA is not dynamically stable because of the absence of intercalator in the cavity between GC/GC consecutive base pairs.

To study the effects of intercalation on the complex and DNA, the structures of the free complex and DNA were compared respectively with their corresponding structures extracted from the adduct. As shown in Table 1, along with the intercalation of complex into DNA, the geometric parameters of the complex change slightly, in which all the key bond lengths are decreased lightly. As shown in Table 2, the structure of DNA shows large variations in the inserting process, especially in the GC/GC step where a cavity can exist stably in presence of the complex. These behaviors could be explained by two kinds of interactions. One is the $\pi-\pi$ staking interaction between HPB ligand of complex and base pairs, in which the distances 
from the centroid of intercalative ligand to the planes of two neighboring base pairs are $3.35 \AA$ and $3.26 \AA$, respectively (see Figure S7a in SI9). The other is the polar contact interactions of $L$-Ala ligand and $\mathrm{Cu}$ center with DNA, which involves two hydrogen bonds $\mathrm{O} 4 \cdots \mathrm{H} 13$ and $\mathrm{O} 2 \cdots \mathrm{H} 13$ with the distance of $2.7 \AA$ and $1.8 \AA$, respectively, and a polar contact $\mathrm{Cu} \cdots \mathrm{O} 2$ with the distance of $3.4 \AA$ (see Figure $\mathrm{S} 7 \mathrm{~b}$ in SI9). These interactions are obvious different from the docking results, which indicates that the MD simulation is necessary for the accurate estimation of intercalation. In addition, the lengthening and unwinding of the DNA due to intercalation is consistent with the increase of DNA viscosity during its interaction with copper complex, and the structural parameters of DNA can help us understand the hydrodynamic result at a molecular level (see Table 2).

Theoretical absorption spectroscopy. We firstly investigated the absorption spectra in the presence of DNA according to the existing analytical method. As shown in Figure 4a, the spectra of the complex and adduct are plotted by solid line and dashed lines, respectively. The simulated absorption band for adduct is strong at $320 \mathrm{~nm}$, which is in a satisfying agreement with the experimental absorption band observed about $331 \mathrm{~nm}$. The small difference between calculated spectrum and experimental one was also observed in other TDDFT studies on the intercalation of metal complex into DNA ${ }^{10.12}$. However, when we attempted to interpret the dynamic changing process of UV spectrum based on TDDFT method, we found that the calculated absorption bands of the complex (see red line in Figure 4a) not only showed a strong hypochromism, but also a large red shift $(\Delta \lambda \approx 13 \mathrm{~nm})$ after forming the adduct. 
Obviously, the calculated result disagrees with our experimental finding in which only a minor red shift $(\Delta \lambda \approx 4 \mathrm{~nm})$ was observed. The large deviation of calculated value from the experimental value is caused by the shortage of the analytical method. As we know, the absorbance of DNA itself is eliminated for measuring the absorption spectra of complex in the experiments, but this factor is not considered in the existing method. In addition, the UV spectra of metallointercalator/DNA interaction system involve the absorbance of free complex and the absorbance of metallointercalator-DNA adduct. Therefore, for accurately predicting the absorption spectra of metallointercalator/DNA intercalation system, we proposed a new mathematical model with the following equation:

$$
\mathrm{A}_{\text {interaction }}=a \% \mathrm{~A}_{\text {aduuct }}+(1-a \%) \mathrm{A}_{\text {complex }}-a \% \mathrm{~A}_{\mathrm{GC}}
$$

Here $\mathrm{A}_{\text {adduct, }}, \mathrm{A}_{\text {complex }}$ and $\mathrm{A}_{\mathrm{GC}}$, is respectively the calculated absorbance of adduct, complex and $\mathrm{GC} / \mathrm{GC}$ base pairs. The $a \%$ is the proportion of the intercalated complex in all of complex. As the increase of $a$ value from 0 to 100, it means that the proportion of intercalated complex continuously increases with the gradual adding DNA into complex solution in the experiments.

According to this equation, the spectra were simulated with the gradual increase of $a$ value from 0 to 100 by the step of 10 . The simulated absorption spectra are shown in Figure $4 \mathrm{~b}$. First of all, we noted that the change of absorption band could be divided into two steps. In the first step, the proportion of intercalated complex increases from $0 \%$ to $70 \%$, in which the absorption band presents a strong 
hypochromism with a slight and slow red shift $(\Delta \lambda \approx 6 \mathrm{~nm})$. This changing characteristic of simulated spectra agrees well with our experimental result (see Figure 1a). In the second step, the proportion of intercalated complex increases from $70 \%$ to $100 \%$, in which the absorption band presents a strong hypochromism with a large and fast red shift $(\Delta \lambda \approx 7 \mathrm{~nm})$. The fast red shift was not observed in our experiment since the relatively weak DNA-binding affinity of $[\mathrm{Cu}(\mathrm{HPB})(L-\mathrm{Ala})]^{+}$ complex, but this change was observed at a high [DNA]/[metallointercalator] ratio in some similar experiments ${ }^{19}$. We found the root cause of this phenomenon is the additivity of absorbance in the experiment. As shown in Figure 4a, the simulated results show that the absorption peak of adduct is much weaker than that of complex, and the two peaks are very close. Therefore, in the experiment, when the [DNA]/[metallointercalator] ratio is low, there is relatively small number of metallointercalator-DNA adduct in the solution, so the absorption peak of adduct is very weak and covered by the peak of the complex. As a result, the spectrum of interaction system is similar to the spectrum of free complex and changes slowly with the increase of $[\mathrm{DNA}] /[$ metallointercalator $]$ ratio. But when the concentration ratio increases to a high extent, the free complex molecules are obviously decreased and even all of them intercalate into DNA to form the adduct molecules. At this stage, the spectrum of interaction system is similar to the spectrum of adduct and shows a fast red shift.

To further explore the mechanism of these phenomena, the frontier orbitals involved in the electron transitions of the complex and adduct were inspected. The 
oscillator strengths ( $\mathrm{f} \geq 0.06)$, main orbital transition contributions $(\geq 10 \%)$, computed orbital energies (E/hartree), orbital character and simulated bands of complex and adduct are listed in Table 3. As shown in the table, for the free complex, there is only one electron-transfer manner that the electrons transfer from the $\pi$ orbital of HPB ligand to antibonding $\pi^{*}$ orbital of HPB ligand at $306.0 \mathrm{~nm}$. For adduct, there are two electron-transfer manners: (1) electrons transfer from $\pi$ orbital of HPB ligand and DNA to $\pi^{*}$ orbital of HPB ligand at $341.9 \mathrm{~nm}$. (2) Electrons transfer from $\pi$ orbital of DNA to $\pi^{*}$ orbital of HPB ligand at $315.0 \mathrm{~nm}$. The calculation results show that after intercalation of the complex into DNA, the characters and energies of lowest unoccupied molecular orbitals (LUMOs) corresponding to $\pi^{*}$ orbital of HPB ligand have little change, but the characters of occupied molecular orbitals have obvious change and all the corresponding energies of $\pi$ orbitals are increased. Therefore, the red shift of the absorption spectra is due to the increase of $\pi$ orbital energy caused by the coupling of the $\pi$ orbital of the intercalated ligand with the $\pi$ orbital of DNA. This cause of red shift of spectra contradicts the previous inference that the decrease of $\pi^{*}$ orbital energy caused by the coupling of the $\pi^{*}$ orbital of the intercalated ligand with the $\pi$ orbital of $\mathrm{DNA}^{38}$, although both result in the decrease of the $\pi-\pi^{*}$ transitions energy.. In addition, the results show that the intermolecular (DNA-to-complex) charge transfer is significantly weaker than intramolecular (HPB-to-HPB) charge transfer, which results in the hypochromic effect of absorption peaks. 


\section{CONCLUSIONS}

In this work, we have extended the force filed parameters for $\mathrm{Cu}$ (II) to allow simulations involving the metal-ligand coordination bonds. The MD-simulated complex structure is well consistent with the experimental one, and even some bond parameters are closer to the experimental data than DFT results, which suggests that RESP charges and the new AMBER force field parameters for the copper complex evaluated in this work are reliable. The initial structure of metallointercalator-DNA adduct obtained from the molecular docking was relaxed by MD simulation. The dynamical equilibrium during $10 \mathrm{~ns}$ simulations indicated that $[\mathrm{Cu}(\mathrm{HPB})(L-\mathrm{Ala})]^{+}$ complex could insert into DNA and the adduct could exist stably in the solution. The adduct structure in MD simulation results, as compared with the initial structure, has a relatively large variation, which implies that the MD simulation is necessary for the accurate estimation of intercalation.

A new analytical method considering the reference solution and the dynamically changing process of the absorption spectrum with the addition of DNA to complex was proposed. According to this method, we successfully simulated the gradual hypochromism and red shift of the absorption spectra for complex/DNA intercalation. The front part of the simulated absorption bands is in good agreement with our experimental observations. The variation of red shift in the absorption spectra predicted by us is slow first and fast later, which has been presented in some similar 
reports ${ }^{19}$. We found that the root cause of this phenomenon was the additivity of absorbance in the experiment, and gave a rational explanation for this phenomenon.

The analyses of the frontier orbital reveal that the red shift of the absorption spectra is due to the increase of $\pi$ orbital energy caused by the coupling of the $\pi$ orbital of the intercalated ligand with the $\pi$ orbital of DNA. Moreover, the reason of hypochromic effect of absorption peaks is that the intermolecular (DNA-to-complex) charge transfer is significantly weaker than intramolecular (ligand-to-ligand) charge transfer. These causes of red shift and hypochromism of the absorption spectra is completely different from the previous inference ${ }^{38}$.

\section{ASSOCIATED CONTENT}

Supporting Information. Additional information as noted in text. This material is available free of charge via the Internet at http://pubs.acs.org.

\section{ACKNOWLEDGMENTS}

This work was supported by the key Academic Program of the 3rd phase "211 Project" of the South China Agricultural University, National Science Foundation of China (21173088) and Natural Science Foundation of Guangdong Province (10151064201000016). 


\section{REFERENCES}

1. Barton, J. K.; Danishefsky, A.; Goldberg, J., J. Am. Chem. Soc. 1984, 106, 2172-2176.

2. Barton, J. K.; Olmon, E. D.; Sontz, P. A., Coord. Chem. Rev. 2011, 255, 619-634.

3. (a) Jenkins, Y.; Friedman, A. E.; Turro, N. J.; Barton, J. K., Biochemistry (Mosc). 1992, 31, 10809-10816.(b) Friedman, A. E.; Chambron, J. C.; Sauvage, J. P.; Turro, N. J.; Barton, J. K., J. Am. Chem. Soc. 1990, 112, 4960-4962.

4. (a) Uma Maheswari, P.; Palaniandavar, M., J. Inorg. Biochem. 2004, 98, 219-230.(b) Burrows, C. J.; Muller, J. G., Chem. Rev. 1998, 98, 1109-1152.

5. (a) Natile, G.; Coluccia, M., Coord. Chem. Rev. 2001, 216-217, 383-410.(b) Chen, H.; Parkinson, J. A.; Parsons, S.; Coxall, R. A.; Gould, R. O.; Sadler, P. J., J. Am. Chem. Soc. 2002, 124, 3064-3082.

6. (a) Biver, T.; Secco, F.; Venturini, M., Coord. Chem. Rev. 2008, 252, 1163-1177.(b) Pierard, F.; Kirsch-De Mesmaeker, A., Inorg. Chem. Commun. 2006, 9, 111-126.(c) Liu, H. K.; Sadler, P. J., Acc. Chem. Res. 2011, 44, 349-359.

7. (a) Gago, F., Methods 1998, 14, 277-292.(b) Lerman, L. S., J. Mol. Biol. 1961, 3, 18-IN14.(c) Demeunynck, M.; Bailly, C.; Wilson, W. D., Small molecule DNA and RNA binders: from synthesis to nucleic acid complexes. Wiley-Vch: 2003; Vol. 2.(d) Chaurasiya, K. R.; Paramanathan, T.; McCauley, M. J.; Williams, M. C., Phys. Life Rev. 2010, 7, 299-341.

8. (a) Sokkar, P.; Sathis, V.; Ramachandran, M., J. Mol. Model. 2012, 18, 1691-1700.(b) Tai, H. C.; Brodbeck, R.; Kasparkova, J.; Farrer, N. J.; Brabec, V.; Sadler, P. J.; Deeth, R. J., Inorg. Chem. 2012 , $51,6830-6841$.

9. (a) Baruah, H.; Barry, C. G.; Bierbach, U., Curr. Top. Med. Chem. 2004, 4, 1537-1549.(b) Ji, L. N.; Zou, X. H.; Liu, J. G., Coord. Chem. Rev. 2001, 216, 513-536.(c) Lincoln, P.; Norden, B., J. Phys. Chem. B 1998, 102, 9583-9594.(d) Lu, Y. M.; Le, X. Y., Chinese J. Inorg. Chem. 2011, 27, 199-213.(e) Liu, Y.; Hammitt, R.; Lutterman, D. A.; Thummel, R. P.; Turro, C., Inorg. Chem. 2007, $46,6011-6021$.

10. (a) Miao, T. F.; Li, S.; Li, J.; Zheng, K. C., J. Inorg. Biochem. 2012, 109, 16-25.(b) Miao, T. F.; Li, S.; Xu, L. C.; Zheng, K. C., Comput. Theor. Chem. 2011, 976, 209-214.

11. Wang, F. F.; Zhao, D. X.; Yang, Z. Z.; Jiao, Y.; Yang, P., Comput. Theor. Chem. 2011, 970, 36-41. 
12. Ambrosek, D.; Loos, P. F.; Assfeld, X.; Daniel, C., J. Inorg. Biochem. 2010, 104, 893-901.

13. Mutter, S. T.; Platts, J. A., J. Phys. Chem. A 2011, 115, 11293-11302.

14. (a) Orozco, M.; Noy, A.; Pérez, A., Curr. Opin. Struct. Biol. 2008, 18, 185-193.(b) Norberg, J.; Nilsson, L., Acc. Chem. Res. 2002, 35, 465-472.(c) Auffinger, P.; Westhof, E., Curr. Opin. Struct. Biol. 1998, 8, 227-236.

15. Robertazzi, A.; Vargiu, A. V.; Magistrato, A.; Ruggerone, P.; Carloni, P.; de Hoog, P.; Reedijk, J., J. Phys. Chem. B 2009, 113, 10881-10890.

16. (a) David, L.; Amara, P.; Field, M. J.; Major, F., J. Comput. Aided Mol. Des. 2002, 16, 635-651.(b) Zhu, Y. Y.; Wang, Y.; Chen, G. J.; Zhan, C. G., Theor. Chem. Acc. 2009, 122, 167-178.(c) Zhu, Y. Y.; Su, Y. W.; Li, X. C.; Wang, Y.; Chen, G. J., Chem. Phys. Lett. 2008, 455, 354-360.

17. (a) Baruah, H.; Bierbach, U., J. Biol. Inorg. Chem. 2004, 9, 335-344.(b) Vargiu, A. V.; Magistrato, A., Inorg. Chem. 2012, 51, 2046-2057.

18. (a) Fantacci, S.; De Angelis, F.; Sgamellotti, A.; Marrone, A.; Re, N., J. Am. Chem. Soc. 2005, 127, 14144-14145.(b) Very, T.; Despax, S.; Hebraud, P.; Monari, A.; Assfeld, X., Phys. Chem. Chem. Phys. 2012, 14, 12496-12504.

19. (a) Ramakrishnan, S.; Shakthipriya, D.; Suresh, E.; Periasamy, V. S.; Akbarsha, M. A.; Palaniandavar, M., Inorg. Chem. 2011, 50, 6458-6471.(b) Li, L. Y.; Jia, H. N.; Yu, H. J.; Du, K. J.; Lin, Q. T.; Qiu, K. Q.; Chao, H.; Ji, L. N., J. Inorg. Biochem. 2012, 113, 31-39.(c) Sun, J.; Wu, S.; Chen, H. Y.; Gao, F.; Liu, J.; Ji, L. N.; Mao, Z. W., Polyhedron 2011, 30, 1953-1959.(d) Du, K. J.; Wang, J. Q.; Kou, J. F.; Li, G. Y.; Wang, L. L.; Chao, H.; Ji, L. N., Eur. J. Med. Chem. 2011, 46, 1056-1065.

20. Lu, Y.; Ou, Z.; Hu, W.; Le, X., Acta Chim. Sinica 2012, 70, 973-979.

21. Kohn, W.; Becke, A. D.; Parr, R. G., J. Phys. Chem. 1996, 100, 12974-12980.

22. (a) Becke, A. D., J. Chem. Phys. 1993, 98, 5648-5652.(b) Lee, C.; Yang, W.; Parr, R. G., Phys. Rev. $B 1988,37,785$.

23. Ditchfield, R.; Hehre, W.; Pople, J. A., J. Chem. Phys. 1971, 54, 724-728.

24. Frisch, M. J.; Trucks, G. W.; Schlegel, H. B.; Scuseria, G. E.; Robb, M. A.; Cheeseman, J. R.; Montgomery, J. A.; Vreven, T.; Kudin, K. N.; Burant, J. C.; Millam, J. M.; Iyengar, S. S.; Tomasi, J.; Barone, V.; Mennucci, B.; Cossi, M.; Scalmani, G.; Rega, N.; Petersson, G. A.; Nakatsuji, H.; Hada, M.; Ehara, M.; Toyota, K.; Fukuda, R.; Hasegawa, J.; Ishida, M.; Nakajima, T.; Honda, Y.; Kitao, O.; 
Nakai, H.; Klene, M.; Li, X.; Knox, J. E.; Hratchian, H. P.; Cross, J. B.; Bakken, V.; Adamo, C.; Jaramillo, J.; Gomperts, R.; Stratmann, R. E.; Yazyev, O.; Austin, A. J.; Cammi, R.; Pomelli, C.; Ochterski, J. W.; Ayala, P. Y.; Morokuma, K.; Voth, G. A.; Salvador, P.; Dannenberg, J. J.; Zakrzewski, V. G.; Dapprich, S.; Daniels, A. D.; Strain, M. C.; Farkas, O.; Malick, D. K.; Rabuck, A. D.; Raghavachari, K.; Foresman, J. B.; Ortiz, J. V.; Cui, Q.; Baboul, A. G.; Clifford, S.; Cioslowski, J.; Stefanov, B. B.; Liu, G.; Liashenko, A.; Piskorz, P.; Komaromi, I.; Martin, R. L.; Fox, D. J.; Keith, T.; Laham, A.; Peng, C. Y.; Nanayakkara, A.; Challacombe, M.; Gill, P. M. W.; Johnson, B.; Chen, W.; Wong, M. W.; Gonzalez, C.; Pople, J. A., Gaussian 03,. 2003.

25. Kielkopf, C. L.; Erkkila, K. E.; Hudson, B. P.; Barton, J. K.; Rees, D. C., Nat. Struct. Mol. Biol. $2000,7,117-121$

26. Ricci, C. G.; Netz, P. A., J. Chem. Inf. Model. 2009, 49, 1925-1935.

27. Wang, J.; Wolf, R. M.; Caldwell, J. W.; Kollman, P. A.; Case, D. A., J. Comput. Chem. 2004, 25, 1157-1174.

28. Bayly, C. I.; Cieplak, P.; Cornell, W.; Kollman, P. A., J. Phys. Chem. 1993, 97, 10269-10280.

29. Besler, B. H.; Merz, K. M.; Kollman, P. A., J. Comput. Chem. 1990, 11, 431-439.

30. Hermann, T.; Heumann, H., RNA 1995, 1, 1009-1017.

31. Darden, T.; York, D.; Pedersen, L., J. Phys. Chem. 1993, 98, 10089-10092.

32. D.A. Case, T. A. D., T.E. Cheatham, III, C.L. Simmerling, J. Wang, R.E. Duke, R. Luo, R.C. Walker, W. Zhang, K.M. Merz, B. Roberts, S. Hayik, A. Roitberg, G. Seabra, J. Swails, A.W. Goetz, I. Kolossvai, K.F. Wong, F. Paesani, J. Vanicek, R.M. Wolf, J. Liu, X. Wu, S.R. Brozell, T. Steinbrecher, H. Gohlke, Q. Cai, X. Ye, J. Wang, M.-J. Hsieh, G. Cui, D.R. Roe, D.H. Mathews, M.G. Seetin, R. Salomon-Ferrer, C. Sagui, V. Babin, T. Luchko, S. Gusarov, A. Kovalenko, and P.A. Kollman (2012), AMBER 12, University of California, San Francisco.

33. Lu, X. J.; Shakked, Z.; Olson, W. K., J. Mol. Biol. 2000, 300, 819-840.

34. O'Boyle, N. M.; Tenderholt, A. L.; Langner, K. M., J. Comput. Chem. 2008, 29, 839-845.

35. (a) Rajendiran, V.; Karthik, R.; Palaniandavar, M.; Stoeckli-Evans, H.; Periasamy, V. S.; Akbarsha, M. A.; Srinag, B. S.; Krishnamurthy, H., Inorg. Chem. 2007, 46, 8208-8221.(b) Senthil Raja, D.; Bhuvanesh, N. S. P.; Natarajan, K., Inorg. Chem. 2011.

36. Cohen, G.; Eisenberg, H., Biopolymers 1969, 8, 45-55.

37. Satyanarayana, S.; Dabrowiak, J. C.; Chaires, J. B., Biochemistry (Mosc). 1992, 31, 9319-9324. 
38. (a) Azab, H. A.; El-Korashy, S. A.; Anwar, Z. M.; Hussein, B. H. M.; Khairy, G. M., J. Chem. Eng. Data 2010, 55, 3130-3141.(b) Gao, E.; Zhu, M. C.; Liu, L.; Huang, Y.; Wang, L.; Shi, C. Y.; Zhang, W. Z.; Sun, Y. G., Inorg. Chem. 2010, 49, 3261-3270.(c) Mudasir; Wijaya, K.; Wahyuni, E. T.; Inoue, H.; Yoshioka, N., Spectrochim. Acta A 2007, 66, 163-170.(d) Chen, C. Y.; Chen, K.; Long, Q.; Ma, M. H.; Ding, F., Spectros. Int. J. 2009, 23, 103-111.(e) Terenzi, A.; Barone, G.; Silvestri, A.; Giuliani, A. M.; Ruggirello, A.; Liveri, V. T., J. Inorg. Biochem. 2009, 103, 1-9.(f) Tabassum, S.; Amir, S.; Arjmand, F.; Pettinari, C.; Marchetti, F.; Masciocchi, N.; Lupidi, G.; Pettinari, R., Eur. J. Med. Chem. 2012, DOI: 10.1016/j.ejmech.2012.08.019. 
Table 1. Some selected bond lengths and angles of $[\mathrm{Cu}(\mathrm{HPB})(L-\mathrm{Ala})]^{+}$complex.

\begin{tabular}{lllll}
\hline & $\operatorname{Exp}^{[a]}$ & $D F T$ & $M D^{[b]}$ & MD $^{[\mathrm{cc}]}$ \\
\hline Cu-N1 & 1.99 & 2.02 & 1.99 & 1.97 \\
Cu-N3 & 2.01 & 2.05 & 2.04 & 2.03 \\
Cu-N4 & 1.97 & 2.04 & 1.98 & 1.96 \\
Cu-O1 & 1.93 & 1.88 & 1.87 & 1.84 \\
N1-Cu-N3 & 81.5 & 81.2 & 82.0 & 82.2 \\
N3-Cu-O1 & 92.6 & 90.2 & 89.8 & 89.4 \\
O1-Cu-N4 & 84.3 & 84.1 & 83.8 & 84.1 \\
N1-Cu-N4 & 101.2 & 104.6 & 104.6 & 104.5 \\
N1-Cu-O1 & 171.5 & 171.0 & 170.5 & 170.6 \\
O1-N3-N1-N4 & 1.9 & 2.6 & 4.6 & 4.1 \\
\hline
\end{tabular}

[a] The mean value of two structural units in the crystal cell, taken from reference 20 of our previous work. [b] Average structure of MD simulative free complex. [c] Complex structure extracted from the average structure of MD simulative DNA-complex adduct. 
Table 2. Interbasepair step parameters for the DNA fragment d(5'-GTTGCAAC-3') from the crystal structure and the average structure of MD simulations. ${ }^{[a]}$

\begin{tabular}{|c|c|c|c|c|c|c|c|}
\hline & \multirow{2}{*}{ step } & \multicolumn{3}{|c|}{ Rise $(\AA)$} & \multicolumn{3}{|c|}{ Twist ( $\left(^{\circ}\right)$} \\
\hline & & $\overline{\operatorname{Exp}^{[b]}}$ & $\mathrm{MD}^{[\mathrm{c}]}$ & $\mathrm{MD}^{[\mathrm{d}]}$ & $\operatorname{Exp}^{[b]}$ & $\mathrm{MD}^{[\mathrm{c}]}$ & $\mathrm{MD}^{[\mathrm{d}]}$ \\
\hline 1 & $\mathrm{GT} / \mathrm{AC}$ & 3.32 & 3.40 & 3.42 & 33.77 & 34.78 & 33.75 \\
\hline 2 & TT/AA & 3.19 & 3.33 & 3.33 & 37.00 & 37.18 & 36.79 \\
\hline 3 & TG/CA & 3.06 & 3.09 & 3.16 & 44.11 & 20.29 & 24.61 \\
\hline 4 & GC/GC & 7.37 & 3.39 & 6.85 & 17.99 & 37.54 & 18.21 \\
\hline 5 & $\mathrm{CA} / \mathrm{TG}$ & 3.14 & 3.45 & 3.49 & 49.38 & 27.35 & 34.23 \\
\hline 6 & AA/TT & 3.16 & 3.33 & 3.30 & 29.71 & 38.12 & 37.52 \\
\hline 7 & $\mathrm{AC} / \mathrm{GT}$ & 3.32 & 3.20 & 3.26 & 33.16 & 28.68 & 30.07 \\
\hline
\end{tabular}

[a] Twist, twist between two consecutive base pairs; Rise, distance between two consecutive base pairs. The analysis of these parameters was performed with X3DNA. [b] DNA fragment derived from crystal structure of original DNA. [c] Average structure of MD simulative free DNA without copper complex. [d] DNA structure extracted from the average structure of MD simulative DNA-complex adduct. 
Table 3. Calculated oscillator strengths ( $\mathrm{f} \geq 0.06$ ), main orbital transition contributions ( $\geq 10 \%$ ), corresponding orbital energies (Hartreee), orbital character and simulated bands of complex and adduct using TDDFT method at the B3LYP/3-21G(d) level as well as the experimental values.

\begin{tabular}{|c|c|c|c|c|c|c|c|}
\hline & $\begin{array}{l}\lambda / \mathrm{nm} \\
\text { (calc.) }\end{array}$ & $f$ & $\begin{array}{c}\text { Major } \\
\text { contribution }\end{array}$ & $\begin{array}{l}\text { Orbital } \\
\text { energies }\end{array}$ & Character $^{[\mathrm{a}]}$ & $\begin{array}{l}\lambda / \mathrm{nm} \\
\text { (simu. }\end{array}$ & $\begin{array}{l}\lambda / \mathrm{nm} \\
\text { (expt.) }\end{array}$ \\
\hline \multirow[t]{4}{*}{ Complex } & 306.0 & 0.56 & $\mathrm{H}-3(\alpha) \rightarrow \mathrm{L}(\alpha)$ & $-0.254 \rightarrow-0.088$ & $\pi_{\mathrm{int}} \rightarrow \pi^{*}{ }_{\mathrm{int}}$ & 307 & 331 \\
\hline & & & $\mathrm{H}-2(\alpha) \rightarrow \mathrm{L}(\alpha)$ & $-0.253 \rightarrow-0.088$ & $\pi_{\mathrm{int}} \rightarrow \pi^{*}{ }_{\mathrm{int}}$ & & \\
\hline & & & $\mathrm{H}-3(\alpha) \rightarrow \mathrm{L}(\beta)$ & $-0.254 \rightarrow-0.088$ & $\pi_{\mathrm{int}} \rightarrow \pi^{*}{ }_{\mathrm{int}}$ & & \\
\hline & & & $H-2(\beta) \rightarrow L(\beta)$ & $-0.253 \rightarrow-0.088$ & $\pi_{\mathrm{int}} \rightarrow \pi^{*}{ }_{\mathrm{int}}$ & & \\
\hline \multirow[t]{7}{*}{ Adduct } & 341.9 & 0.111 & $\mathrm{H}-12(\alpha) \rightarrow \mathrm{L}(\alpha)$ & $-0.238 \rightarrow-0.084$ & $\pi_{\mathrm{int}}+\pi_{\mathrm{DNA}} \rightarrow \pi^{*}{ }_{\mathrm{int}}$ & 320 & 335 \\
\hline & & & $\mathrm{H}-13(\beta) \rightarrow \mathrm{L}(\beta)$ & $-0.238 \rightarrow-0.083$ & $\pi_{\mathrm{int}}+\pi_{\mathrm{DNA}} \rightarrow \pi^{*}{ }_{\mathrm{int}}$ & & \\
\hline & & & $\mathrm{H}-11(\beta) \rightarrow \mathrm{L}(\beta)$ & $-0.235 \rightarrow-0.083$ & $\pi_{\mathrm{int}}+\pi_{\mathrm{DNA}} \rightarrow \pi^{*}{ }_{\mathrm{int}}$ & & \\
\hline & 315.0 & 0.07 & $\mathrm{H}-21(\alpha) \rightarrow \mathrm{L}(\alpha)$ & $-0.253 \rightarrow-0.084$ & $\pi_{\mathrm{DNA}} \rightarrow \pi^{*}{ }_{\mathrm{int}}$ & & \\
\hline & & & $\mathrm{H}-20(\alpha) \rightarrow \mathrm{L}(\alpha)$ & $-0.248 \rightarrow-0.084$ & $\pi_{\mathrm{DNA}} \rightarrow \pi^{*}{ }_{\mathrm{int}}$ & & \\
\hline & & & $\mathrm{H}-18(\alpha) \rightarrow \mathrm{L}(\alpha)$ & $-0.246 \rightarrow-0.084$ & $\pi_{\mathrm{DNA}} \rightarrow \pi^{*}{ }_{\mathrm{int}}$ & & \\
\hline & & & $\mathrm{H}-17(\alpha) \rightarrow \mathrm{L}(\alpha)$ & $-0.246 \rightarrow-0.084$ & $\pi_{\mathrm{DNA}} \rightarrow \pi^{*}{ }_{\mathrm{int}}$ & & \\
\hline
\end{tabular}

[a] The $\pi_{\text {int }}$ and $\pi_{\text {DNA }}$ express the $\pi$-bond on the intercalative ligand (HPB ligand) of complex and DNA, respectively. 


\section{Figure captions}

Figure 1. (a) Absorption spectra of the complex $\left(5 \times 10^{-5} \mathrm{M}\right)$ in the absence of CT-DNA $(\mathrm{R}=0)$ and in the presence of increasing amounts of CT-DNA $(\mathrm{R}=1 \sim 30)$. $\mathrm{R}=[\mathrm{DNA}] /[$ complex $]$ (b) A fitting of the absorbance data used to obtain the binding constants.

Figure 2. The optimized geometry of $[\mathrm{Cu}(\mathrm{HPB})(L-\mathrm{Ala})]^{+}$with atomic labels for structural parameters.

Figure 3. The structure change of DNA during the MD simulations. The initial structure derived from the experimental data and the MD simulation results for free DNA and DNA-complex adduct are their average structure.

Figure 4. Absorption spectra of the complex in the absence (solid line) and presence (dashed lines) of DNA. (a) The results obtained by the existing method. (b) Absorption spectra with subtraction of the corresponding DNA absorbance. 

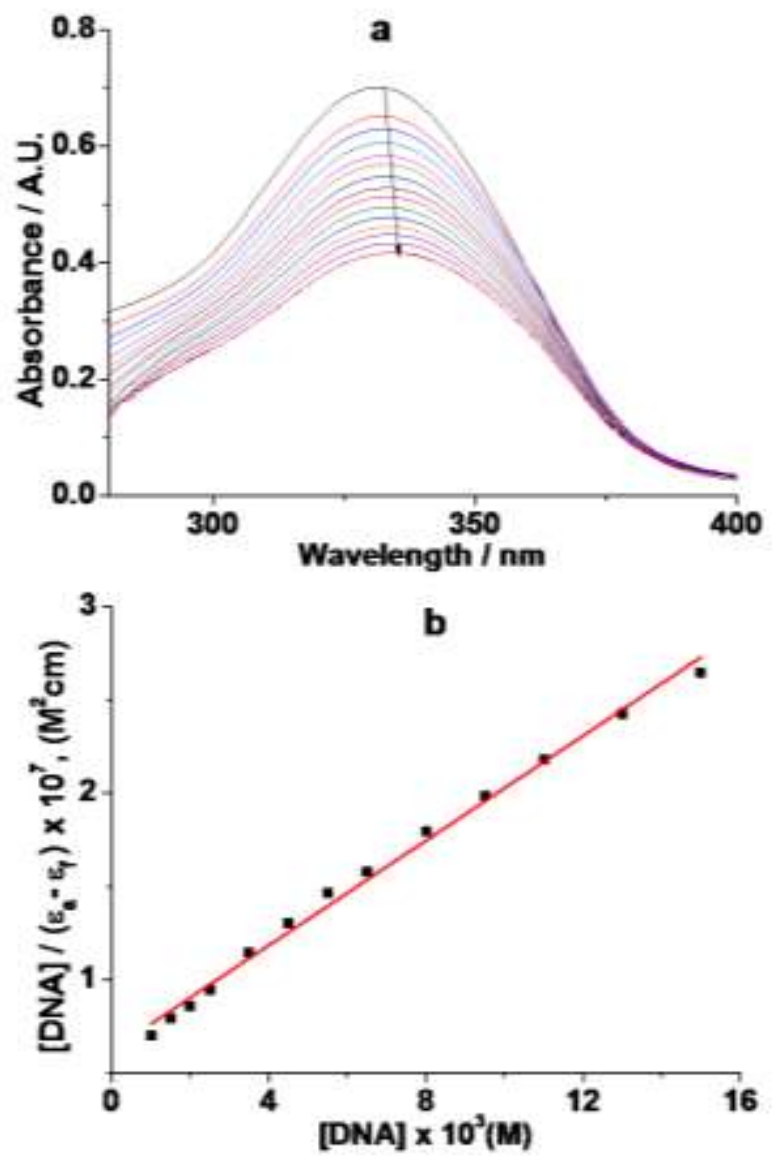

Figure 1. 


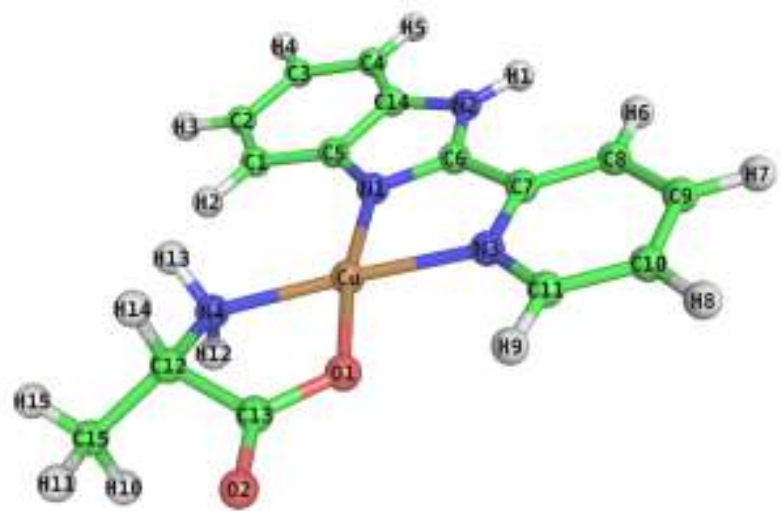

Figure 2. 


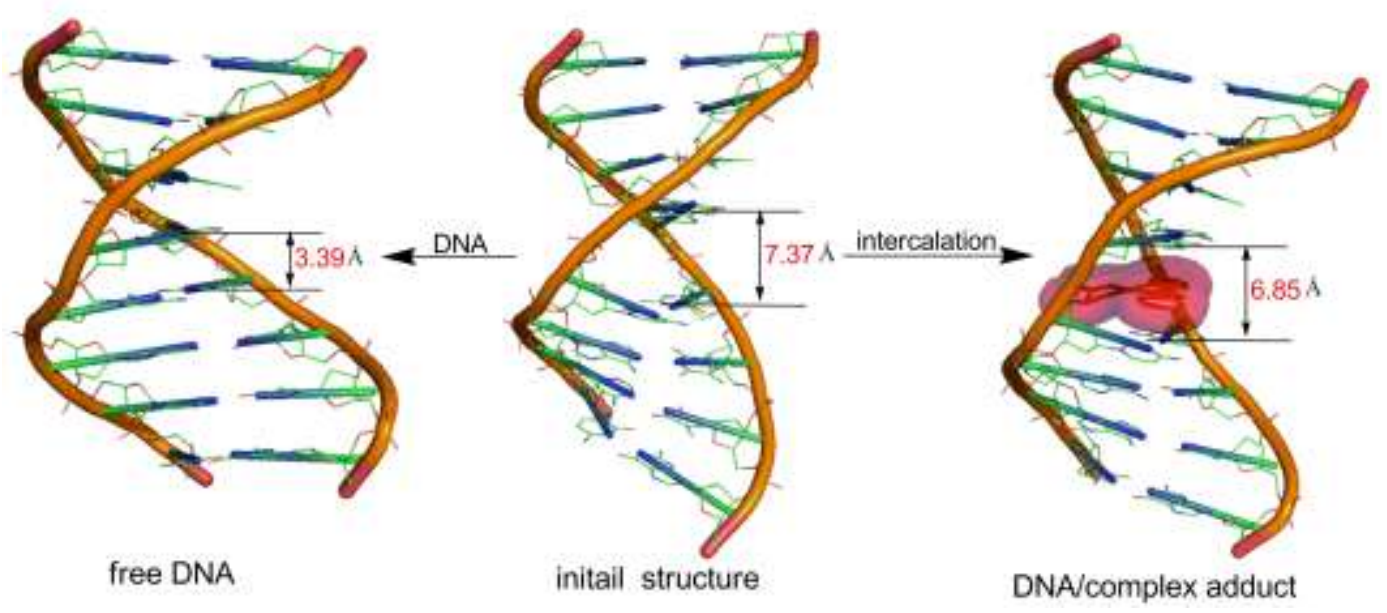

Figure 3. 

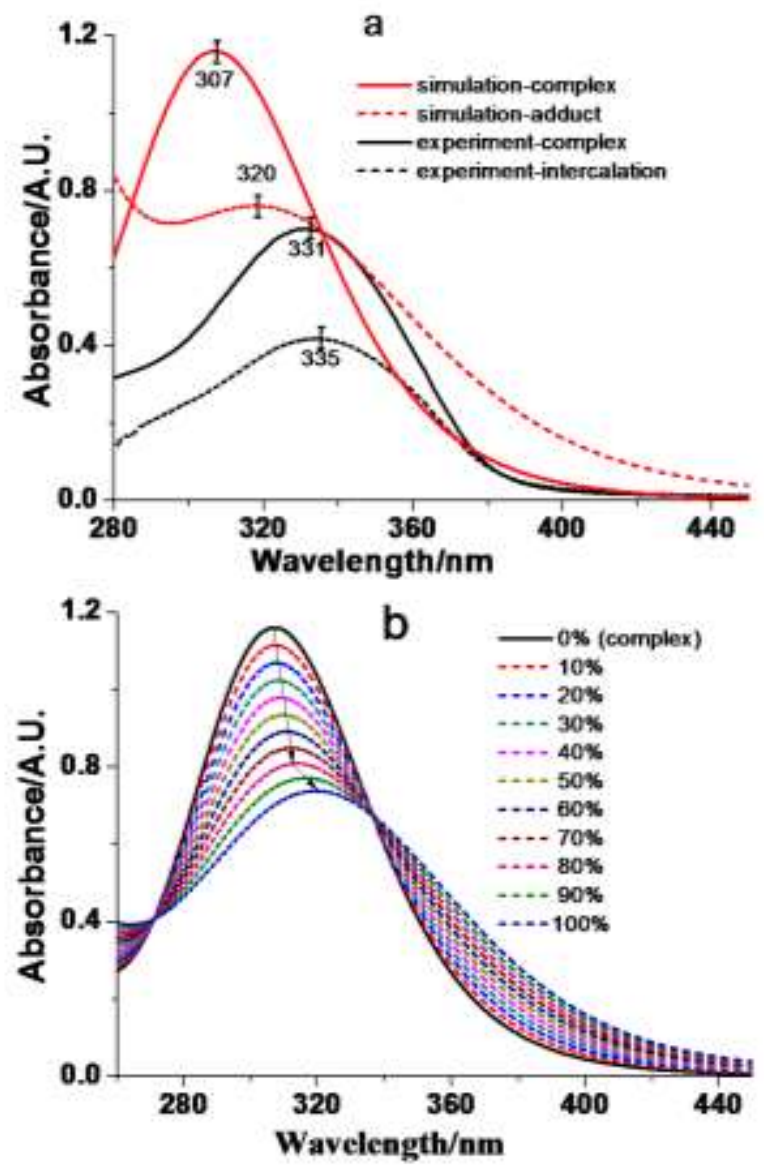

Figure 4. 
TOC graphic

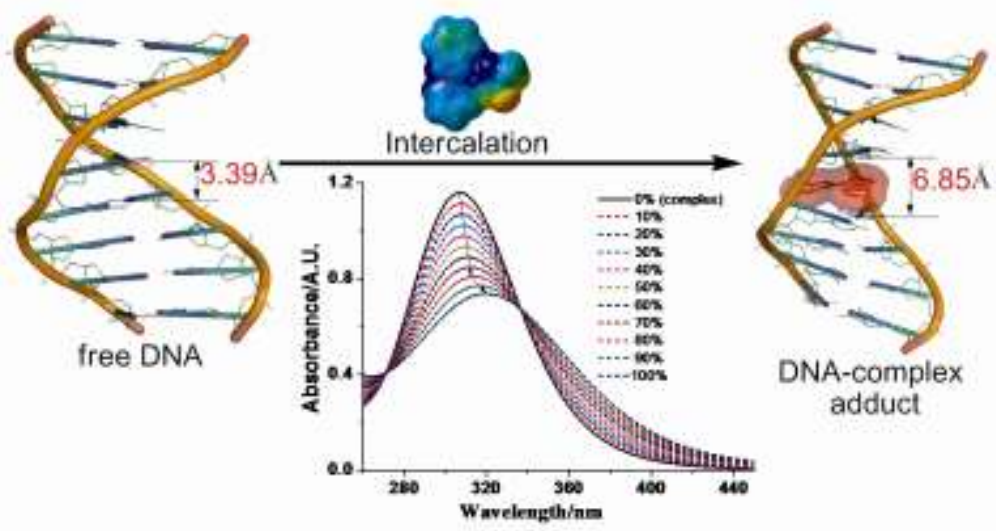

